\title{
DR BERTIL ALMER
}

Bertil Almer has passed away. His inaugural dissertation of 1922 dealt with the theory of functions of two complex variables. From I 925 to his retirement in I964, he was chief actuary in one of the greatest insurance offices for General Insurance in Sweden and from I929 a member of several committées common to the Swedish Tarif Companies. Especially he was interested in Motor Insurance, and made the chief contribution to creation of the tarifs in this line. Above all he was a theoretician and has published many papers of outstanding theoretical value. His deep knowledge in pure mathematics has been of great importance for his theoretical work mainly centered on a generalized form of the theory of risk. His most important papers were published in the Transactions of the International Congress of Actuaries 1957 and I960, in Skand. Akt. Tidskr. I96r, Astin Bulletin r963 and his last paper, read to the Luzern-Colloquium, is to be published in Astin Bulletin 1966. He has developed the idea of risk elements constituted by potential accidents regarded as random functions each associated with a claim probability and a claim distribution. He has proved that every claim distribution with any desired precision can be approximated by an upper and a lower bound in the form of an exponential polynomial. His expansion of the distribution function of the accumulated amounts of claims in a given period of time is based on the assumption of a claim distribution in this form. He has a specific terminology by aid of which he has been able to describe his theory of risk in an extremely general form. His developments are, therefore, of extreme interest to a reader who will not spare the heavy work of grasping his lines of thought. Such a reader is certain to be convinced of the importance of his pioneer work in the field. Requiescat in pace.

Stockholm, the i6th of Nobember i965 Card Philipson 